\title{
PREPARO DO SOLO EM ÁREAS DE PRODUÇÃO DE GRÃOS, SILAGEM E PASTEJO: EFEITO NA RESISTÊNCIA TÊNSIL E FRIABILIDADE DE AGREGADOS ${ }^{(1)}$
}

\author{
Marina Araújo Bavoso ${ }^{(2)}$, Neyde Fabíola Balarezo Giarola ${ }^{(3)}$, Cássio \\ Antônio Tormena ${ }^{(4)} \&$ Volnei Pauletti ${ }^{(5)}$
}

\begin{abstract}
RESUMO
A compreensão e a quantificação do impacto do uso e manejo na qualidade do solo são fundamentais no desenvolvimento e seleção de sistemas de produção agrícola sustentáveis. O objetivo do presente estudo foi avaliar a qualidade estrutural de um Latossolo Bruno argiloso submetido a diferentes sistemas de produção e preparo do solo por meio da resistência tênsil (RT) e friabilidade (F) de agregados. O estudo foi realizado no município de Castro, Estado do Paraná, em três sistemas de produção e sete tipos de preparo de solo, estabelecidos em um delineamento fatorial em blocos casualizados. Os sistemas avaliados foram: (SP I) - plantio de azevém para cobertura do solo (no inverno) e milho para a produção de grãos (no verão); (SP II) - plantio de azevém para a produção de silagem pré-secada e milho para a produção de grãos; e (SP III) - utilização de azevém como forrageira para pastejo animal e milho para a produção de grãos. Em cada sistema de produção foram avaliados sete tipos de preparo do solo: (G1) - grade aradora no inverno a $0,15 \mathrm{~m}$ de profundidade; (G2) - grade aradora no inverno e no verão a $0,15 \mathrm{~m}$ de profundidade; (Arado) - arado de discos a 0,20 m de profundidade; (Subsolador Asa Laser) - subsolador com ponteiras tipo asa até 0,45 m; (Subsolador) - subsolador até a profundidade de $0,80 \mathrm{~m}$; (Aerador) - aerador de solo Aeromix ${ }^{\circledR}$ com profundidade efetiva de mobilização de 0,15 m; e (SPD) - Sistema Plantio Direto, em que a semeadura do azevém foi realizada com disco duplo e a do milho com
\end{abstract}

\footnotetext{
(1) Recebido para publicação em maio de 2009 e aprovado em outubro de 2009.

${ }^{(2)}$ Aluna do Curso de Agronomia, Universidade Estadual de Ponta Grossa - UEPG. Av. Gal. Carlos Cavalcanti 4748, CEP 84030900 Ponta Grossa (PR). E-mail: marinabavoso@hotmail.com

(3) Professor Adjunto do Departamento de Ciência do Solo e Engenharia Agrícola, Universidade Estadual de Ponta Grossa UEPG. Av. Gal. Carlos Cavalcanti 4748, CEP 84030-900 Ponta Grossa (PR). E-mail: neydef@uepg.br

(4) Professor Adjunto do Departamento de Agronomia, Universidade Estadual de Maringá - UEM. Av. Colombo 5790, CEP 87020900 Maringá (PR). E-mail: catormena@uem.br

(5) Professor Adjunto do Departamento de Solos e Engenharia Agrícola, Universidade Federal do Paraná - UFPR. Rua dos Funcionários 1540, CEP 80035-050 Curitiba (PR). E-mail: vpauletti@ufpr.br
} 
haste sulcadora. Um bloco de solo $(0,20 \times 0,15 \times 0,07 \mathrm{~m})$ de cada parcela experimental foi manualmente destorroado em seus agregados naturais, os quais foram secos ao ar por $24 \mathrm{~h}$ e passados em peneiras com diâmetros de 12,5 e $19 \mathrm{~mm}$. Quarenta agregados de cada bloco foram selecionados e submetidos a testes de tensão indireta com dinamômetro digital eletrônico de precisão (Lutron FG-20 kg), para determinação de RT e quantificação da F. Os resultados demonstraram que a RT foi influenciada pelos sistemas de produção e tipos de preparo do solo. $O$ menor valor de RT foi verificado no solo sob Pastejo, enquanto o Sistema Plantio Direto apresentou o maior valor de RT. A friabilidade não distinguiu os sistemas de produção e tipos de preparo de solo estudados.

Termos de indexação: qualidade física do solo, estrutura do solo, manejo do solo, sistemas de produção integrada.

\title{
SUMMARY: SOIL TILLAGE IN GRAIN AND SILAGE-PRODUCING AREAS AND PASTURE: EFFECT ON TENSILE STRENGTH AND AGGREGATE FRIABILITY
}

\begin{abstract}
The understanding and quantification of soil use and management on the soil physical quality are important to develop and select sustainable agricultural systems. The purpose of this study was to evaluate the structural quality of a clayey Brazilian Oxisol under different production and soil tillage systems by measuring the tensile strength (TS) and to quantify aggregate friability $(F)$. The study was conducted in Castro, Paraná state, in southern Brazil, using three production systems and seven soil tillage types, in a randomized block design. The following production systems were evaluated: (PS I) - ryegrass for soil cover (winter) and corn for grain production (summer); (PS II) ryegrass for haylage/silage and corn for grain production; and (PS III) - ryegrass for grazing and corn for grain production. Seven types of soil tillage were evaluated in each system: (G1) - plow harrow in winter, depth $0.15 \mathrm{~m}$; (G2) - plow harrow in winter and summer, depth $0.15 \mathrm{~m}$; (Plow) - disk plow, depth $0.20 \mathrm{~m}$; (Laser wing subsoiler) - subsoiler wing tips, to a depth of $0.45 \mathrm{~m}$; (Subsoiler) - subsoiler, depth $0.80 \mathrm{~m}$; (Aerator) - soil

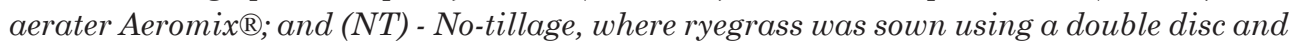
corn with a coulter. From each experimental plot soil blocks $(0.20 \times 0.15 \times 0.07 \mathrm{~m})$ were taken which were broken up by hand in their natural aggregates. Then, the aggregates were air-dried for $24 \mathrm{~h}$ and passed through sieves with diameters of 12.5 and $19 \mathrm{~mm}$. Forty aggregates from each block were selected and tested for indirect tension to determine TS and quantify F. TS was influenced by the production systems and soil tillage types. The lowest and the highest TS values were found in the soil under grazing and the NT system, respectively. Friability was less sensitive to differentiate production systems and soil tillage types.
\end{abstract}

Index terms: soil physical quality, soil structure, soil management, integrated production systems.

\section{INTRODUÇÃO}

Na região Centro-Sul do Estado do Paraná estabeleceram-se sistemas de produção com elevada eficiência e qualidade das atividades agrícolas integradas com a pecuária leiteira. Nesses sistemas, milho e azevém são comumente cultivados para a produção de silagem e, ou, feno, com o intuito de sustentar o confinamento ou semiconfinamento do rebanho. Essas culturas dominam as áreas de integração lavoura-pecuária (ILP), em razão da adaptação às condições locais e da qualidade nutricional do material produzido (Santos et al., 2001).
No inverno, as condições favoráveis de clima e solo dominantes no Sul do Brasil beneficiam a produção com alto rendimento de matéria seca de forrageiras e geram uma alternativa de renda e de redução de custos na produção de leite (Moraes et al., 2002). No entanto, a adoção dessa prática é bastante limitada em razão de alguns paradigmas: (a) animais em pastejo não conseguem manter elevadas produções de leite; e (b) o pastoreio em áreas agrícolas promove a compactação do solo e estabelece uma elevada exportação de nutrientes, o que pode alterar a eficiência agronômica e econômica da produção de grãos no período do verão (Souto, 2006). Silva et al. (2000) já haviam relatado 
que sistemas de ILP podem modificar de forma deletéria as propriedades físicas do solo que determinam o crescimento radicular e a produtividade das culturas, em função do tráfego de máquinas, pisoteio animal e preparo do solo. Para Marchão et al. (2007), a seleção inadequada e a utilização indiscriminada de diversos tipos de preparo do solo na ILP também alteram a qualidade física dos solos e, simultaneamente, a manutenção da produtividade do sistema.

Diversos tipos de preparo do solo são empregados nos sistemas que integram agricultura e pecuária. Os preparos conservacionistas mobilizam minimamente o solo e mantêm a maior parte dos resíduos da cultura anterior como estratégia para conservação de solo e água e obtenção de elevadas produtividades (Araújo et al., 2004). A escarificação ou a subsolagem são adotadas como práticas de preparo mínimo com o intuito de romperem camadas compactadas, por meio da redução da densidade e da resistência do solo à penetração, do aumento da macroporosidade e da infiltração de água no solo (De Maria et al., 1999; Sazaki et al., 2005). No preparo convencional, os arados de discos promovem inversão da leiva com intensa fragmentação da estrutura do solo. As grades mobilizam o solo das camadas superficiais, mas não promovem a inversão da leiva com a mesma eficiência dos arados. A aração, quando realizada após a passagem da grade pesada, proporciona maior incorporação e mistura de material na camada preparada, podendo atingir maior profundidade (Falleiro et al., 2003).

O impacto dos sistemas de preparo e manejo dos solos tem sido avaliado por meio de medidas de propriedades físicas, como a densidade e a porosidade do solo (Silva et al., 2000; Tormena et al., 2004; Carneiro et al., 2009), a resistência do solo à penetração (Tavares Filho \& Ribon, 2008) e a distribuição dos agregados em classes de tamanho ou sua estabilidade em água (Carpenedo \& Mielniczuk, 1990; Castro Filho et al., 1998). A RT é outra medida sensível aos efeitos de sistemas de uso e manejo na estrutura do solo (Chan, 1995; Watts \& Dexter, 1998; Blanco-Canqui et al., 2005) e vem sendo utilizada no estudo de qualidade de solos agrícolas do Brasil (Imhoff et al., 2002; Giarola et al., 2003; Lima et al., 2005; Tormena et al., 2008a,b). A RT é influenciada por diversos fatores, destacando-se o teor de água do solo (Kay \&
Dexter, 1992), a composição química e concentração da solução do solo (Rahimi et al., 2000), o teor de argila e mineralogia (Ley et al., 1993; Imhoff et al., 2002), a presença de argila dispersa (Kay \& Dexter, 1992) e o teor de matéria orgânica do solo (Imhoff et al., 2002). A friabilidade (F) ou heterogeneidade da RT dos agregados também é outro indicador da qualidade estrutural e física do solo, uma vez que a condição de solo friável é desejável para a germinação das sementes, o crescimento das plântulas e o estabelecimento das culturas. A F indica a tendência de uma massa de solo a se desfazer em agregados de tamanhos menores sob a aplicação de um estresse ou carga (Watts \& Dexter, 1998), em função dos planos de fraqueza ou zonas de falhas na estrutura do solo (Dexter \& Watts, 2000).

A compreensão e a quantificação do impacto dos sistemas de uso e manejo do solo na sua qualidade física são fundamentais no desenvolvimento e na seleção de sistemas agrícolas sustentáveis (Dexter \& Youngs, 1992). Este trabalho testou a hipótese de que sistemas de produção sem pisoteio de animais e revolvimento de camadas do solo apresentam maior qualidade estrutural da camada arável do solo. O objetivo foi avaliar a qualidade estrutural de um Latossolo Bruno argiloso da região Centro-Sul do Paraná, conduzido sob diferentes sistemas de produção e tipos de preparo do solo, por meio da resistência tênsil e friabilidade de agregados.

\section{MATERIAL E MÉTODOS}

O estudo foi conduzido em área experimental da Fundação ABC, localizada no município de Castro, Paraná $\left(24^{\circ} 47^{\prime} 28^{\prime}\right.$ S e $50^{\circ} 00^{\prime} 25^{\prime}$ W). O clima da região é classificado como Cfb (Köppen), ou seja, subtropical úmido com duas estações bem definidas, com verões úmidos, presença de geadas no inverno, precipitação pluvial média anual de $1.500 \mathrm{~mm}$ e temperatura média anual de $18{ }^{\circ} \mathrm{C}$ (IAPAR, 2000). O experimento foi implantado na safra 2004/2005, em um Latossolo Bruno argiloso (Embrapa, 2006) situado em relevo plano $\left(0,01 \mathrm{~m} \mathrm{~m}^{-1}\right.$ de declividade). Os resultados das análises do solo (Embrapa, 1997) efetuadas antes da instalação do experimento são apresentados no quadro 1 .

Quadro 1. Propriedades químicas e físicas das camadas de 0-10 e 10-20 cm do Latossolo Bruno utilizado no experimento

\begin{tabular}{|c|c|c|c|c|c|c|c|c|c|c|c|c|c|c|c|}
\hline Profundidade & $P$ resina & MO & $\mathbf{p} \mathrm{H}_{\mathrm{CaCl}_{2}}$ & $\mathbf{H}+\mathbf{A l}$ & $\mathrm{Al}^{3+}$ & $\mathbf{K}^{+}$ & $\mathrm{Ca}^{2+}$ & $\mathbf{M g}^{2+}$ & SB & CTC & $\mathbf{V}$ & $\mathrm{Al}^{3+}$ & Argila & Areia & Silte \\
\hline $\mathrm{m}$ & $\mathrm{mg} \mathrm{dm}{ }^{-3}$ & $\mathrm{~g} \mathrm{dm}$ & & - & - & - & $\mathrm{mol}_{\mathrm{c}} \mathrm{d}$ & $m^{-3}$ & & - & - & - & & $\mathrm{g} \mathrm{kg}^{-1}$ & ${ }^{\prime}$ \\
\hline $0,00-0,10$ & 85 & 50 & 4,7 & 72 & 1 & 4,2 & 37 & 10 & 51,2 & 123,2 & 42 & 1,92 & 439 & 384 & 177 \\
\hline $0,10 \_0,20$ & 44 & 41 & 4,6 & 72 & 2 & 2,7 & 22 & 8 & 32,7 & 104,7 & 31 & 5,76 & 488 & 357 & 155 \\
\hline
\end{tabular}


O delineamento experimental foi o de blocos completos casualizados, com três sistemas de produção (SP), sete tipos de preparo de solo e quatro repetições, totalizando 84 parcelas experimentais. Os sistemas de produção selecionados são amplamente utilizados pelos agricultores da região: (SP I) - azevém para cobertura do solo (no inverno) e milho para a produção de grãos (no verão); (SP II) - azevém para a produção de silagem pré-secada e milho para a produção de grãos; e (SP III) - azevém como forrageira para pastejo animal e milho para a produção de grãos. Em cada sistema de produção foram avaliados sete tipos de preparo do solo: (G1) - grade aradora no inverno a $0,15 \mathrm{~m}$ de profundidade; (G2) - grade aradora no inverno e no verão a $0,15 \mathrm{~m}$ de profundidade; (Arado) - arado de discos a 0,20 m de profundidade; (Subsolador Asa Laser) - subsolador com ponteiras tipo asa até $0,45 \mathrm{~m}$ de profundidade; (Subsolador) - subsolador até a profundidade de 0,80 m; (Aerador) - aerador de solo Aeromix ${ }^{\circledR}$ com profundidade efetiva de mobilização de 0,15 m; e (SPD) - Sistema Plantio Direto em que a mobilização do solo ocorre apenas na linha de semeadura. Nos três sistemas de produção a semeadura do azevém foi realizada com disco duplo a $0,03 \mathrm{~m}$ de profundidade, e a do milho, com haste sulcadora a $0,04 \mathrm{~m}$ de profundidade, sendo a deposição do adubo efetuada a cerca de 0,10 m. Os sistemas de preparo G1, G2 e Arado foram complementados com grade niveladora após a semeadura da cultura de inverno. A aplicação de corretivos e a adubação das culturas foram realizadas de acordo com os resultados de análise de solo. Épocas de semeadura, controle de plantas daninhas e tratamentos fitossanitários foram definidos de acordo com as recomendações técnicas para cada cultura.

$\mathrm{O}$ azevém foi pastejado por bovinos da raça holandesa, com lotação ajustada para a oferta de matéria seca de $2,5 \%$ do peso animal e pastejo contínuo de três dias. A entrada dos animais e o corte do azevém ocorreram quando as plantas apresentavam entre 0,20 e 0,25 m de altura. Realizaram-se dois a três pastejos por ano, geralmente nos meses de junho, julho e agosto. O último pastejo do azevém foi realizado em período que permitiu um rebrote de aproximadamente sete dias, depois do qual foi feita a dessecação. Trinta dias depois da dessecação, foi realizada a semeadura do milho.

Três safras após a implantação do experimento (2007/2008), foram coletados blocos indeformados de solo $(0,15 \times 0,20 \times 0,07 \mathrm{~m})$ com o auxílio de uma pá, na camada superficial $(0,0-0,15 \mathrm{~m})$ de cada unidade experimental. No laboratório, os blocos foram secos ao ar e destorroados, manualmente, em seus agregados naturais, tomando o cuidado de aplicar apenas a força necessária para que eles se fragmentassem em seus planos de fraqueza naturais. Com o auxílio das peneiras de 12,5 e $19 \mathrm{~mm}$ de diâmetro de malha, foram selecionados agregados com diâmetro médio de $15,75 \mathrm{~mm}$, os quais foram secos em estufa a $40^{\circ} \mathrm{C}$ por $48 \mathrm{~h}$, para homogeneização do teor de água das amostras de agregados.
Quanto às medidas de resistência tênsil (RT), foram utilizados 40 agregados de cada bloco. Cada agregado foi pesado individualmente e submetido a teste de tensão indireta, para determinação da (RT). Para isso, foi utilizado um dinamômetro digital eletrônico de precisão (Lutron FG $20 \mathrm{~kg}$ ), composto por célula de carga com carga nominal de 20 kgf ligada a um microcomputador, para aquisição e armazenamento dos dados. As medidas foram determinadas em agregados colocados, na posição mais estável, entre duas placas metálicas: a inferior, fixa, e a superior, móvel. A placa móvel era responsável pela aplicação progressiva da força sobre os agregados até a ruptura, ou seja, até a formação de uma fissura contínua ao longo do diâmetro polar do agregado.

A RT foi calculada por meio da equação 1 , conforme Dexter \& Kroesbergen (1985):

$$
R T=0,576 \times\left(\frac{P}{D^{2}}\right)
$$

em que $R T$ é a resistência tênsil, usualmente representada pela unidade $\mathrm{kPa} ; 0,576$ é o coeficiente de proporcionalidade, resultante da relação entre a carga compressiva aplicada e o estresse tênsil gerado no interior do agregado; $\mathrm{P}$ é a força necessária para a quebra tênsil do agregado (N); e $D$ é o diâmetro efetivo (m).

O diâmetro efetivo $(D)$ foi calculado utilizando a proposta de Dexter \& Kroesbergen (1985), conforme a equação 2:

$$
D=D m \times\left(\frac{M}{M m}\right)^{\frac{1}{3}}
$$

sendo $M$ a massa do agregado individual (g); $M m$ é a massa média dos agregados em cada tratamento (g); e $D m$ é o diâmetro médio dos agregados $(\mathrm{mm})$, definido pela média dos tamanhos das peneiras $[(12,5+19,0) /$ $2=15,75 \mathrm{~mm}]$.

A friabilidade do solo foi estimada pelo método do coeficiente de variação proposto por Watts \& Dexter (1998), indicada na equação 3:

$$
F=\frac{\sigma_{Y}}{Y} \pm \frac{\sigma_{Y}}{Y \sqrt{2 n}}
$$

na qual $F$ é friabilidade do solo; $\sigma_{\mathrm{y}}$ é o desvio-padrão dos valores medidos da resistência tênsil; $Y$ é a média dos valores medidos de resistência tênsil; e $\mathrm{n}$ é o número de repetições, sendo o segundo termo o erropadrão do coeficiente de variação.

A classificação da friabilidade foi realizada conforme Imhoff et al. (2002) em classes: não friável $(\mathrm{F}<0,10)$, ligeiramente friável $(\mathrm{F}=0,10$ a 0,20$)$, friável $(\mathrm{F}=0,20$ a 0,50$)$, muito friável $(\mathrm{F}=0,50 \mathrm{a}$ $0,80)$ e mecanicamente instável $(\mathrm{F}>0,80)$. 
Depois da determinação da RT, o material de solo residual foi utilizado para as determinações da distribuição granulométrica, do teor de argila dispersa em água e do teor de água residual dos agregados, conforme Embrapa (1997). O teor de carbono orgânico total foi determinado pelo método de combustão seca, utilizando-se um analisador de $\mathrm{C}$ e N, denominado TruSpec CHN, da LECO Equipamentos ${ }^{\circledR}$ (Schumacher, 2002).

Realizaram-se, previamente, testes de normalidade dos dados das variáveis: resistência tênsil, teor de carbono orgânico total, teor de água residual dos agregados e argila dispersa em água $(n=84)$, por meio do procedimento PROC UNIVARIATE (SAS, 1999), em que se adotou o grau de confiança de 0,05 para o teste Shapiro-Wilk. Em seguida, procedeu-se à análise de variância e ao teste de comparação de médias (Tukey), por meio do pacote estatístico SAS (SAS, 1999).

\section{RESULTADOS E DISCUSSÃO}

Os momentos estatísticos dos atributos dos agregados do Latossolo Bruno argiloso são apresentados no quadro 2 . O coeficiente de variação (CV) da resistência tênsil foi de 26,66 \% - similar aos índices encontrados por Imhoff et al. (2000), Dexter \& Kroerbergen (1985) e Imhoff et al. (2002). Os CVs das frações areia, silte e argila foram baixos, destacandose a maior variabilidade no teor de silte do solo, provavelmente associada à variabilidade no teor de carbono orgânico do solo (COS). O aumento no teor de COS resulta em microagregados mais estáveis, dificultando o processo de dispersão, o que, segundo Ferreira et al. (1999), resulta na quantificação de maiores teores de silte por ocasião da análise granulométrica em Latossolos. Os elevados teores de COS, neste solo, também explicam a variação do teor de água nos agregados do solo.

Os resultados do teste de normalidade indicaram que os valores de resistência tênsil de agregados, COS, teores de argila dispersa em água e água residual, independentemente dos sistemas de produção e de preparo, apresentaram distribuição normal dos dados originais $(p>W>0,05)$ pelo teste Shapiro-Wilk. Em relação à $\mathrm{RT}$, os resultados foram similares aos obtidos por Dexter \& Watts (2000). Por outro lado, Tormena et al. (2008a,b), Giarola et al. (2003) e Imhoff et al. (2002), constataram distribuição log-normal da RT em diferentes solos do Brasil.

Não foram verificados efeitos estatisticamente significativos dos sistemas de produção e preparo do solo para as variáveis $\mathrm{C}$ orgânico total, argila dispersa em água, argila, silte, areia e teor de água residual. Esses resultados sugerem que as variações de RT deveram-se, exclusivamente, às variações estruturais impostas pelos sistemas de produção e de preparo do solo. A análise de variância indicou efeito estatisticamente significativo dos sistemas de produção e tipos de preparo do solo na RT ( $p>0,05)$, destacandose que a interação sistemas de produção e preparo do solo não foi estatisticamente significativa. Os valores médios de RT para os diferentes sistemas de produção são apresentados na figura 1.

A RT no SP III foi significativamente menor do que no SP II, e a RT nos sistemas SP II e SP III não diferiu daquela do sistema SP I $(p>0,05)$ (Figura 1). No caso do sistema SP II, os maiores valores de RT deveram-se ao maior tráfego de máquinas e implementos necessários ao processamento e à colheita do azevém para produção de silagem pré-secada. $\mathrm{O}$ sistema SP III é equivalente à integração lavourapecuária amplamente disseminada no Sul do Brasil, em que os animais utilizam a forrageira de inverno para o pastejo. Os valores de RT neste solo são baixos comparados àqueles medidos por Giarola et al. (2003), Imhoff et al. (2002) e Tormena et al. (2008a,b), associados às características intrínsecas dos diferentes solos estudados e aos teores de COS mais elevados do Latossolo Bruno utilizado neste estudo.

Os menores valores de RT no SP III podem ser relacionados aos seguintes fatores: (a) o consumo contínuo da forragem (pastejo) estimula o perfilhamento e a rebrota desta e, por sua vez, estabelece maior atividade e crescimento de raízes no

Quadro 2. Momentos estatísticos para as propriedades estudadas nos agregados do solo $(\mathrm{N}=84)$

\begin{tabular}{|c|c|c|c|c|c|c|}
\hline Atributo do solo & Mínimo & Média & Máximo & DP & CV & $W(p>W)$ \\
\hline $\mathrm{C}$ orgânico total $\left(\mathrm{g} \mathrm{kg}^{-1}\right)$ & 20,31 & 30,04 & 40,26 & 0,33 & 10,27 & 0,9102 \\
\hline Argila ( $\left.\mathrm{g} \mathrm{kg}^{-1}\right)$ & 400 & 430 & 480 & 2,10 & 4,36 & -- \\
\hline Silte $\left(\mathrm{g} \mathrm{kg}^{-1}\right)$ & 160 & 200 & 250 & 2,22 & 7,61 & -- \\
\hline Areia $(\mathrm{g} \mathrm{kg} \cdot 1)$ & 340 & 370 & 410 & 1,38 & 3,14 & -- \\
\hline Argila dispersa em água ( $\left.\mathrm{g} \mathrm{kg}^{-1}\right)$ & 43 & 71 & 95 & 2,47 & 35,18 & 0,8464 \\
\hline Teor de água residual (kg kg-1) & 0,0133 & 0,0350 & 0,0757 & 0,0061 & 17,24 & 0,8686 \\
\hline Resistência Tênsil (kPa) & 16,85 & 37,99 & 84,68 & 12,20 & 26,66 & 0,8807 \\
\hline Friabilidade (adimensional) & 0,36 & 0,58 & 2,05 & 0,23 & 20,75 & -- \\
\hline
\end{tabular}




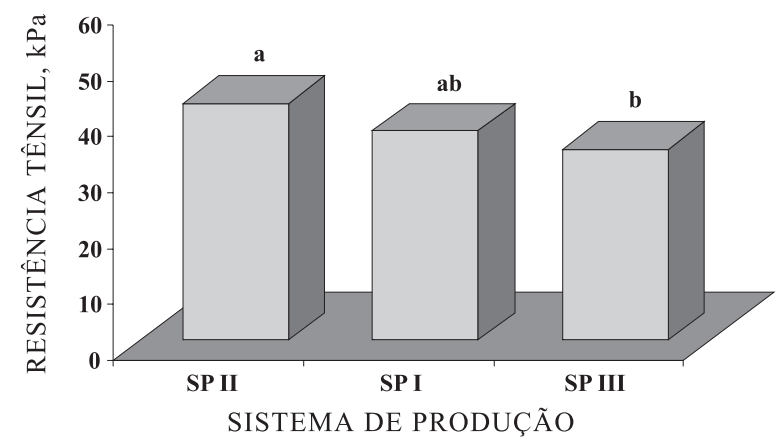

Figura 1. Valores médios de resistência tênsil dos agregados do solo para os sistemas de produção SP I, SP II e SP III. Médias seguidas de letras iguais não diferem entre si pelo teste de Tukey a $5 \%$.

solo; e (b) no período de recuperação da forrageira após o pastejo, o que propicia incremento na área foliar, resultando em aumento no consumo e extração de água no perfil de solo, especialmente nas camadas superficiais, e, por sua vez, em maior intensidade de ciclos de secagem e umedecimento, responsáveis pela criação de microfissuras ou microfraturas nos agregados, determinando redução na RT. Esses processos são possíveis desde que a lotação animal seja adequada e que o manejo dos animais possibilite a regeneração e o acúmulo de fitomassa aérea (Moraes et al., 2002). Também há de se ressaltar que o pastejo da forrageira em condição de elevado teor de água no solo foi evitado, o que poderia estabelecer uma intensa degradação estrutural pelo pisoteio animal (Moraes et al., 2002). Imhoff et al. (2000) já haviam alertado que, em sistemas de produção que envolvem o pastejo, a degradação física do solo causada pelo pisoteio dos animais pode comprometer a sua eficiência. Isso não foi observado neste estudo, devido à adoção de lotação animal adequada, associada com um curto período de pastejo pelos animais. A prática de evitar o pastejo com solo úmido e com baixa disponibilidade de forragem reduz o potencial de degradação física do solo, de acordo com Sarmento et al. (2008).

Independentemente do sistema de produção, os valores de resistência tênsil deste solo são bem menores do que aqueles verificados por Imhoff et al. (2002) e Tormena (2008b) para Latossolos, provavelmente devido aos teores de COS mais elevados e à textura argilosa, que proporcionam qualidade estrutural diferenciada, como descrito e classificado por Calegari (2008), em vertente oposta à do local de estudo: Latossolo argiloso com A húmico apresentando estrutura granular e teores em torno de $40 \mathrm{~g} \mathrm{~kg}^{-1} \mathrm{de}$ COT.

Os valores médios de RT para os diferentes tipos de preparo de solo são apresentados na figura 2 . $\mathrm{O}$ solo sob SPD mostrou valores médios mais elevados de RT em comparação com os de outros sistemas de preparo, à exceção do solo sob preparo com Aerador, que também diferiu significativamente do tratamento em que o preparo foi realizado com grade antecedendo a semeadura das culturas de inverno e verão (G2).

O maior valor de RT em SPD (51,72 kPa) deveuse, provavelmente, ao efeito do tráfego de máquinas (Tavares Filho et al., 2001) associado à não mobilização do solo, quando comparado aos preparos convencionais (G1, G2 e Arado) e aos preparos com mínima mobilização (Subsolador Asa, Subsolador e Aerador). O SPD apresentou RT cerca de $60 \%$ maior que a dos preparos convencionais e entre 44 e $18 \%$ maior que a dos sistemas com mínima mobilização, sugerindo um gradiente de $\mathrm{RT}$ com redução dos seus valores à medida que aumentou a intensidade de mobilização do solo. A mobilização do solo altera a estrutura por meio da quebra nas ligações entre agregados e expõe o solo a secagem e umedecimento, contribuindo para os mecanismos que promovem o arranjo de fendas e microfendas, definindo as zonas de fraqueza na estrutura do solo. De acordo com Tavares-Filho et al. (2001), o preparo mínimo do solo, apesar de não promover o seu revolvimento intenso, altera-lhe a estrutura, pela mobilização efetuada, assim como o revolvimento do solo resulta em perdas de matéria orgânica do solo. No entanto, os resultados deste experimento mostraram que, nesses três anos de experimento e nas condições de solo e ambiente em que foi conduzido o presente trabalho, não foram constatadas diferenças significativas no teor de matéria orgânica do solo entre os sistemas de uso e manejo. Essas constatações permitiram concluir que as alterações estruturais no solo que promoveram as modificações na RT deveram-se às alterações macroestruturais promovidas por esses sistemas, como constatado nos estudos de Blanco-Canqui et al. (2005).

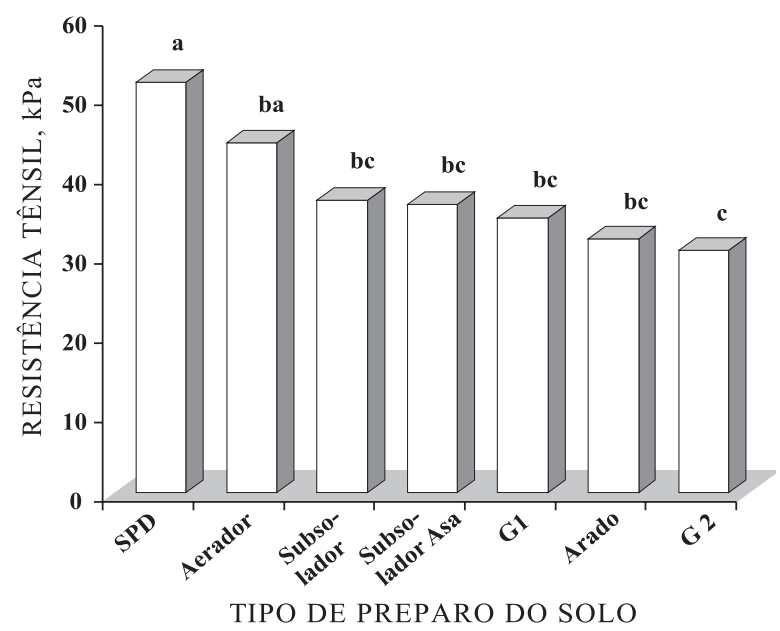

Figura 2. Valores médios de resistência tênsil dos agregados do solo para os preparos de solo G1, G2, Arado, Subsolador Asa, Subsolador e Aerador. Médias seguidas de letras iguais não diferem entre si pelo teste de Tukey a $5 \%$. 
Os valores médios de $\mathrm{F}$ nos sistemas de uso e preparo do solo são apresentados no quadro 3 . Distintamente da RT, não se verificaram diferenças estatisticamente significativas de $\mathrm{F}$ entre os sistemas de uso e preparo do solo.

A amplitude da friabilidade do solo (Quadro 3) em relação aos sistemas de preparo foi de 0,44 (SPD) a 0,70 (G2, Subsolador), valores esses pertencentes à classe friável e muito friável, respectivamente, segundo classificação proposta por Imhoff et al. (2002). Segundo esses autores, valores elevados de friabilidade indicam que agregados de maior tamanho possuem menor resistência tênsil que aqueles de menor tamanho, o que explica a formação de agregados que são mais facilmente fraturados quando submetidos à passagem de grade aradora no inverno e no verão (G2) e ao subsolador em profundidade de até $0,80 \mathrm{~m}$, os quais apresentaram menores valores de $\mathrm{RT}$ e os mais elevados valores de F. Os maiores valores de $\mathrm{RT}$ e os menores de $\mathrm{F}$ foram encontrados em SPD (classificado como Friável) e podem ser justificados pela preservação das ligações entre agregados, devido à não mobilização do solo e, por sua vez, à manutenção da qualidade estrutural. Os valores médios de $\mathrm{F}$ encontrados nos sistemas de uso foram similares aos obtidos por Imhoff et al. (2002) para Latossolo Vermelho distrófico e Latossolo Vermelho eutroférrico cultivados com canade-açúcar no Sudeste do Brasil, indicando que o solo deve requerer reduzida intensidade de cultivo para gerar agregados pequenos e, consequentemente, uma cama de semeadura adequada para germinação e estabelecimento das plantas (Macks et al., 1996).

Os sistemas de produção e preparo de solo não alteraram de forma significativa a friabilidade (Quadro 3), o que se deve à contribuição dos mecanismos que promovem o arranjo da estrutura deste Latossolo, entre os quais pode-se citar o alto teor de COS, proporcionando assim condições adequadas para a cama de semeadura.

Quadro 3. Classificação do solo quanto à friabilidade (F) para sistemas de produção e tipos de preparo do solo

\begin{tabular}{lll}
\hline \multicolumn{1}{c}{$\begin{array}{c}\text { Sistema } \\
\text { de produção }\end{array}$} & $\begin{array}{c}\text { Valor } \\
\text { médio de F }\end{array}$ & $\begin{array}{c}\text { Classificação } \\
\text { da friabilidade }\end{array}$ \\
\hline SP I & 0,54 & $\begin{array}{l}\text { Muito Friável } \\
\text { Muito Friável } \\
\text { SP II }\end{array}$ \\
SP III & 0,61 & Muito Friável \\
Tipo de preparo & 0,58 & \\
\multicolumn{1}{c}{ do solo } & & \\
G1 & & Muito Friável \\
G2 & 0,56 & Muito Friável \\
Arado & 0,70 & $\begin{array}{l}\text { Muito Friável } \\
\text { SPD }\end{array}$ \\
Subsolador Asa & 0,57 & $\begin{array}{l}\text { Muito Friável } \\
\text { Subsolador }\end{array}$ \\
Aerador & 0,44 & Friável Friável \\
\hline
\end{tabular}

\section{CONCLUSÕES}

1. A RT foi influenciada pelos sistemas de produção e de preparo do solo.

2. Entre os sistemas de produção, o maior valor de RT ocorreu no SP II e o menor no SP III.

3. O menor valor de RT foi verificado no solo sob Pastejo, enquanto o Sistema Plantio Direto apresentou o maior valor de RT.

4. A friabilidade não foi sensível para diferenciar os sistemas de produção e preparo do solo.

\section{LITERATURA CITADA}

ARAUJO, M.A.; TORMENA, C.A.; INOUE, T.T. \& COSTA, A.C.S. Efeitos da escarificação na qualidade física de um Latossolo Vermelho distroférrico após treze anos de semeadura direta. R. Bras. Ci. Solo, 28:495-504, 2004.

BLANCO-CANQUI, H.; LAL, R.; OWENS, L.B.; POST, W.M. \& IZAURRALDE, R.C. Mechanical properties and organic carbon of soil aggregates in the Northern Appalachians. Soil Sci. Soc. Am. J., 69:1472-1481, 2005.

CALEGARI, M.R. Ocorrência e significado paleoambiental do Horizonte A húmico em Latossolos. Piracicaba, Escola Superior de Agricultura Luiz de Queiroz, 2008. (Tese de Doutorado)

CARNEIRO, M.A.C.; SOUZA, E.D.; REIS, E.F.; PEREIRA, H.S. \& AZEVEDO, W.R. Atributos físicos, químicos e biológicos de solo de cerrado sob diferentes sistemas de uso e manejo. R. Bras. Ci. Solo, 33:147-157, 2009.

CARPENEDO, V. \& MIELNICZUK, J. Estado de agregação e qualidade de agregados de Latossolos Roxos, submetidos a diferentes sistemas de manejo. R. Bras. Ci. Solo, 14:99105,1990

CASTRO FILHO, C.; MUZILLI, O. \& PODANOSCHI, A.L. Estabilidade dos agregados e sua relação com o teor de carbono orgânico num Latossolo Roxo distrófico, em função de sistemas de plantio, rotações de culturas e métodos de preparo das amostras. R. Bras. Ci. Solo, 22:527538,1998

CHAN, K.Y. Strength characteristics of a potentially hardsetting soil under pasture and conventional tillage in the semi-arid region of Australia. Soil Till. Res., 34:105113,1995

DE MARIA, I.C.; CASTRO, O.M. \& SOUZA DIAS, H. Atributos físicos do solo e crescimento radicular de soja em Latossolo Roxo sob diferentes métodos de preparo do solo. R. Bras. Ci. Solo, 23:703-709, 1999.

DEXTER, A.R. \& KROESBERGEN, B. Methodology for determination of tensile strength of soil aggregates. J. Agric. Eng. Res., 31:139-147, 1985.

DEXTER, A.R. \& WATTS, C. Tensile strength and friability. In: SMITH, K. \& MULLINS, C., eds. Soil and environmental analysis, physical methods. 2.ed. New York, Marcel Dekker, 2000. p.401-430. 
DEXTER, A.R. \& YOUNGS, I.M. Soil physics toward 2000. Soil Till. Res., 24:101-106, 1992.

EMPRESA BRASILEIRA DE PESQUISA AGROPECUÁRIA . EMBRAPA. Centro Nacional de Pesquisa de Solos. Manual de métodos de análise de solos. 2.ed. Rio de Janeiro, 1997. 212p.

EMPRESA BRASILEIRA DE PESQUISA AGROPECUÁRIA EMBRAPA. Sistema brasileiro de classificação de solos. 2.ed. Rio de Janeiro, 2006. 306p.

FALLEIRO, R.M.; SOUZA, C.M.; SILVA, C.S.W.; SEDIYAMA, C.S.; SILVA, A.A. \& FAGUNDES, J.L. Influência dos sistemas de preparo nas propriedades químicas e físicas do solo. R. Bras. Ci. Solo, 27:1097-1104, 2003.

FERREIRA, M.M.; FERNANDES, B. \& CURI, N. Influência da mineralogia da fração argila nas propriedades físicas de Latossolos da Região Sudeste do Brasil. R. Bras. Ci. Solo, 23:515-524, 1999.

GIAROLA, N.F.B.; SILVA, A.P.; IMHOFF, S. \& DEXTER, A.R. Contribution of natural soil compaction on hardsetting behavior. Geoderma, 113:95-108, 2003.

INSTITUTO AGRONÔMICO DO PARANÁ - IAPAR. Cartas climáticas do Paraná: edição ano 2000, versão 1.0 . Londrina, 2000. CD-ROM.IMHOFF, S.; SILVA, A.P. \& DEXTER, A.R. Factors contributing to the tensile strength and friability of oxisols. Soil Sci. Soc. Am. J., 66:16561661,2002

IMHOFF, S.; SILVA, A.P. \& TORMENA, C.A. Aplicação da curva de resistência do solo à penetração no controle da qualidade física de um solo sob pastagem. Pesq. Agropec. Bras., 35:1493-1500, 2000.

IMHOFF,.S.; SILVA, A.P. \& DEXTER, A. Factors contributing to the tensile strength and friability of Oxisols. Soil Sci. Soc. Am. J., 66:1656-1661, 2002

KAY, B.D. \& DEXTER, A.R. The influence of dispersible clay and wetting/drying cycles on the tensile strength of a Red-Brown Earth. Aust. J. Soil Res., 30:297-310, 1992

LEY, G.J.; MULLINS, C.E. \& LAL, R. Effects of soil properties on the strength of weakly structures tropical soils. Soil Till. Res., 28:1-13, 1993.

LIMA, H.V.; SILVA, A.P.; ROMERO, R.E. \& JACOMINE, P.K.T. Comportamento físico de um Argissolo Acinzentado coeso no Estado do Ceará. R. Bras. Ci. Solo, 29:33-40, 2005.

MACKS, S.P.; MURPHY, B.W.; CRESSWELL, H.P. \& KOEN, T.B. Soil friability in relation to management history and suitability for direct drilling. Aust. J. Soil Res., 34:343360, 1996.

MARCHÃO R.L.; BALBINO, L.C.; SILVA, E.M.; SANTOS JUNIOR, J.D.G.; CAROLINO DE SÁ, M.A.; VILELA, L. \& BECQUER, T. Qualidade física de um Latossolo Vermelho sob sistemas de integração lavoura-pecuária no Cerrado. Pesq. Agropec. Bras., 42:873-882, 2007.

MORAES, A.; PELISSARI, A.; ALVES, S.J.; CARVALHO, P.C.F. \& CASSOL, L.C. Integração Lavoura-Pecuária no Sul do Brasil. In: MELLO, N.A. \& ASSMANN, T.S., eds. ENCONTRO DE INTEGRAÇÃO LAVOURA-PECUÁRIA NO SUL DO BRASIL, 1., 2002. p.3-42.
RAHIMI, H.; PAZIRA, E. \& TAJIK, F. Effect of soil organic matter, electrical conductivity and sodium adsorption ratio on tensile strength of aggregates. Soil Till. Res., 54:145$153,2000$.

SANTOS, G.T.; ÍTAVO, L.C.V.; MODESTO, E.C.; JOBIM. C.C. \& DAMASCENO, J.C. Silagens alternativas de resíduos agro-industriais. In: SIMPÓSIO SOBRE PRODUÇÃO E UTILIZAÇÃO DE FORRAGENS CONSERVADAS, Maringá, 2001. Anais. Maringá, UEM/CCA/DZO, 2001. p.262-285.

SARMENTO, P.; RODRIGUES, L.R.A.; CRUZ, M.C.P.; LUGÃO, S.M.B.; CAMPOS, F.P.; CENTURION, J.F. \& FERREIRA, M.E. Atributos químicos e físicos de um Argissolo cultivado com Panicum maximum Jacq. cv. IPR-86 Milênio, sob lotação rotacionada e adubado com nitrogênio. R. Bras. Ci. Solo, 32:183-193, 2008.

SAS Institute. Statistical Analysis System Institute. SAS/STAT Procedure guide for personal computers. Version 5. Cary, 1999.

SAZAKI, C.M.; GONÇALVES, J.L.M. \& BENTIVENHA, S.R.P. Desempenho operacional de hastes subsoladoras em função da ponteira e do tipo do solo. Sci. For., 67:44-52, 2005.

SCHUMACHER, B.A. Methods for the determination of total organic carbon (TOC) in soils and sediments. Las Vegas, USEPA, Ecological Risk Assessment Support Center, Office of Research and Development, 2002.

SILVA, V.R.; REINERT, D.J. \& REICHERT, J.M. Densidade do solo, atributos químicos e sistema radicular do milho afetados pelo pastejo e manejo do solo. R. Bras. Ci. Solo, 24:191-199, 2000

SOUTO, M.S. Pastagem de aveia e azevém na integração lavoura-pecuária: Produção de leite e características do solo. Curitiba, Universidade Federal do Paraná, 2006. (Tese de Mestrado)

TAVARES FILHO, J.; BARBOSA, G.M.C.; GUIMARÃES, M.F. \& FONSECA, I.C.B. Resistência do solo à penetração e desenvolvimento do sistema radicular do milho (Zea mays) sob diferentes sistemas de manejo em um Latossolo Roxo. R. Bras. Ci. Solo, 25:725-730, 2001.

TAVARES FILHO, J. \& RIBON, A.A. Resistência do solo a penetração em relação ao número de amostras e ao tipo de amostragem. R. Bras. Ci. Solo, 32:487-494, 2008.

TORMENA, C.A.; FIDALSKI, J. \& ROSSI JUNIOR, W. Resistência Tênsil e Friabilidade de um Latossolo sob diferentes sistemas de uso. R. Bras. Ci. Solo, 32:33-42, $2008 \mathrm{a}$.

TORMENA, C.A.; ARAÚJO, M.A.; FIDALSKI, J.; IMHOFF, S. \& SILVA, A.P. Quantificação da resistência tênsil e da friabilidade de um Latossolo Vermelho distroférrico sob plantio direto. R. Bras. de Ci. Solo, 32:943-952, 2008b.

TORMENA, C.A.; VIDIGAL FILHO, P.S.; GONCALVES, A.C.A.; ARAÚJO, M.A. \& PINTRO, J.C. Influência de diferentes sistemas de preparo do solo nas propriedades físicas de um Latossolo Vermelho distrófico. R. Bras. Eng. Agríc. Amb., 8:65-71, 2004.

WATTS, C.W. \& DEXTER, A.R. Soil friability: Theory, measurement and the effects of management and organic carbon content. Eur. J. Soil Sci., 49:73-84, 1998. 